facts and to have an educative role. The medical profession, teachers, social workers, psychologists, and parents have responded to the challenge. Our programme is developing but we need the help of more doctors. Our brochure. "The Case for Responsibility," is available on request.-I am, etc.,

S. E. Ellison Chairman, The Responsible Society 28 Portland Place, London $W .1$

SIR, - What a relief it is to read your leading article on the porn industry (30 September, p. 779). Would that all reasonable people make their views abundantly clear, so that action shall be taken to prevent the propagation of filth.-I am, etc.,

Yetminster, Dorset

B. S. C. GASTER

\section{Iatrogenic Cushing's Syndrome}

SIR,-A 42-year-old woman presented in March 1971 with a history of intermittent psoriasis for 16 years. Over the past two years it had become progressively worse and she had an almost generalized exfoliative psoriasis. The skin surface was tense, shiny, and erythematous with marked exfoliation. There were signs of follicular blockage and secondary infection. Though the skin condition certainly posed a problem, the patient's general practitioner (J.McC.) had referred her mainly on account of her Cushingoid appearance.

On questioning, it was discovered that over the past two years the patient had been applying to her total body skin surface cream containing $0.1 \%$ betamethasone 17 -valerate which had been further diluted $1: 8$ with a bland cream. She was issued weekly with $1,000 \mathrm{~g}$ of the prescription and this amount (containing $125 \mathrm{mg}$ betamethasone) was applied weekly between February 1969 and February 1971. On admission to hospital she had a bloated appearance with mooning of the face and marked oedema of the face and ankles. There was a tendency to bruise readily and some muscle weakness. Secondary amenorrhoea had been present since February 1971. These Cushingoid features were thought to have been caused by percutaneous absorption of the steroid preparation.

The steroid application was discontinued on admission and the initial hypertension settled in two weeks (see Table). The blood pressure has remained normal. The initial morning plasma cortisol level, though lower than usual, was not frankly abnormal. Unfortunately the evening cortisol level was not measured on admission. The initial urinary steroids were also low on admission but, like the plasma cortisol, were subsequently normal. Normal menstruation returned after three months.

When long-term application of a potent steroid preparation is stopped a rebound phenomenon takes place and the skin condition deteriorates rapidly. In this case a dilute form of ordinary $1 \%$ hydrocortisone ointment was substituted for the betamethasone cream and applied sparingly twice daily to the lesions. Internal treatment with hydroxyurea was given under supervision. The response to this therapy was good. The exfoliation ceased and the more usual picture of localized plaques of psoriasis emerged. To date the patient has had to have intermittent courses of hydroxyurea and she continues to apply the dilute $1 \%$ hydrocortisone ointment.

The systemic effects of topical steroids have been well documented ${ }^{2}$ as producing both local Cushingoid changes in the skin and pituitary-adrenal axis suppression. These effects are dose dependent and are enhanced by occlusive dressings. The dosage of steroid cream used in this case was $18 \mathrm{mg} /$ day betamethasone for about two years. Lehner and Lyne $^{3}$ have shown no adrenal suppression on a topical oral dose of $0.4 \mathrm{mg} /$ day, so the Cushingoid effect here is attributable to the excessive quantity of preparation used by the patient.

This case report emphasizes the hazards of long-term topical application of highpotency steroid preparations.-We are, etc.,

Agnese Kelly

KEN Nelson MichaEL GOODWIN JACK MCCLUGGAGE

Department of Dermatology,

Belfast City Hospital,

Fitzpatrick, T. B., Griswold, H. C., and Hicks, J. H., Fournal of the

2 ation, 1955, 158, 1149 . Fournal of Medicine, 1965, 273. 831.

fehner, T., and L L. $1969,4,138$.

\section{Treatment of Endocrine Impotence}

SIR,-In my experience androgen therapy for "endocrine impotence" is usually unsuccessful even when the plasma testosterone level is reduced. Dr. A. J. Cooper (1 April, p. 34) called attention to the fact that there is no conclusive evidence that potency in men, once established, depends on testosterone, and Michael has reported ${ }^{1}$ that he was unable to restore sexual behaviour to precastration levels by giving testosterone proprionate. My results in treating endocrine impotence in ageing men with testosterone are disappointing. Such patients are often treated with tranquilizers or sedatives, which only mask the illness.

The testes of young, healthy men produce quite large amounts of oestrogen as well as testosterone. ${ }^{34}$ This is not a fault of nature. Most probably both oestrogen and testosterone are needed for the development and the maintenance of masculine sexual organs and their function. It is difficult to understand why these well-established facts have not been taken into consideration in hormonal therapy. Oestrogen response is

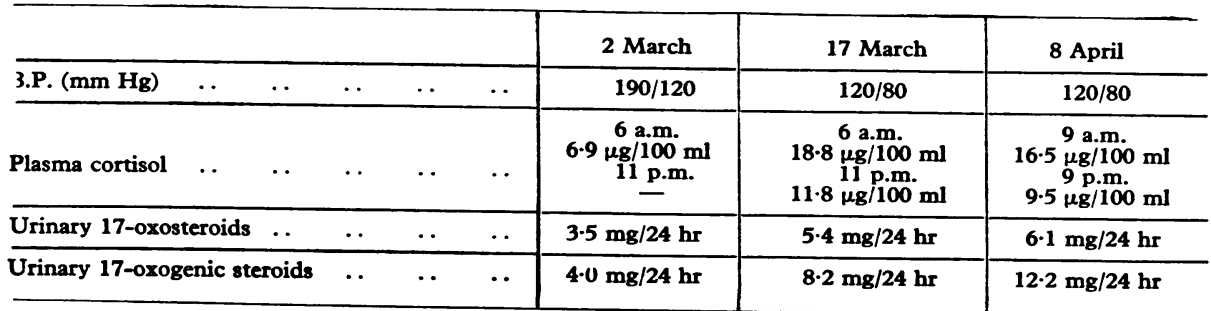

higher than androgen response to stimulation with human chorionic gonadotrophin in young healthy men, but even this finding has been ignored. I have found in 60 selected cases of male climacteric with symptoms of endocrine impotence that treatment with a mixture of oestrogens and androgens has given better results than testosterone alone. The synergistic action of the two substances in the male organism merits attention. Since 1968 I have given oestrone/testosterone parenterally in ratios of $1: 10,1: 20,1: 50$ together with oral oestriol in daily doses ranging from 2 to $4 \mathrm{mg}$. In another group of elderly patients with cardiovascular disease and sexual hypofunction satisfactory results were obtained with injections of either oestrone, nicotinic acid, and testosterone (ratio oestrone to testosterone $1: 20)$ or oestradiol and an anabolic steroid.

Improvement in sexual potency is most probably connected with vasodilatation and a better blood supply to the genital organsthat is to say, local trophicity. Oestrogens augment the blood supply to various parts of the body but primarily to the sexual organs. Further clinical trials with different mixtures of oestrogen and testosterone are needed before the best formula can be established. The advantages of a mixed therapy are: (1) it diminishes the risk of atherosclerosis and coronary thrombosis, because the oestrogenic component lessens the negative influence of testosterone on lipid metabolism; (2) it diminishes the risk of prostatic cancer; and (3) the nicotinic acid augments the lipocatabolic action and has anti-atherosclerosis properties and it causes vascular dilatation. -I am, etc.

JERZY TETER

Department of Endocrinology,

Poland

1 Michael, R. P., in Endocrinology and Human Behaviour. London, Oxford University Press, 1968.

2 Michael, R. P., Personal comm'nication. Lipsett, M.B., in Entocrinology of the Testis. London, Churchill, 196

Maddock, w. O., and Nelson, w. O., fournal of Clinical Endocrinology, 1952, 12, 985.

\section{Management of Diabetes Insipidus in} Pregnancy

SIR,-The wide spectrum of biological activities of the neurohypophysial hormones applies also to vasopressin and can lead to undesirable complications. Thus, though there is a wide difference between the very high antidiuretic and the relatively low uterotonic actions of this hormone therapeutic antidiuretic dosages in diabetes insipidus can threaten the continuation of normal pregnancy. Recently, an analogue of the hormone, (L-deamino-8-d-arginine)vasopressin (DDAVP), has become available, ${ }^{1}$ and reports ${ }^{2}$ have shown that in comparison to the natural peptide DDAVP has a far higher and very prolonged antidiuretic activity with practically no other side effects on any smooth muscle. The different biological spectrum of DDAVP is a great improvement in treating pregnant patients with diabetes insipidus, as the following case illustrates:

A 30-year-old nullipara with a past history of hyperthyroidism developed acute diabetes insipidus a fortnight after a severe head injury from a car accident in the sixth month of pregnancy. Her untreated water turnover showed a 


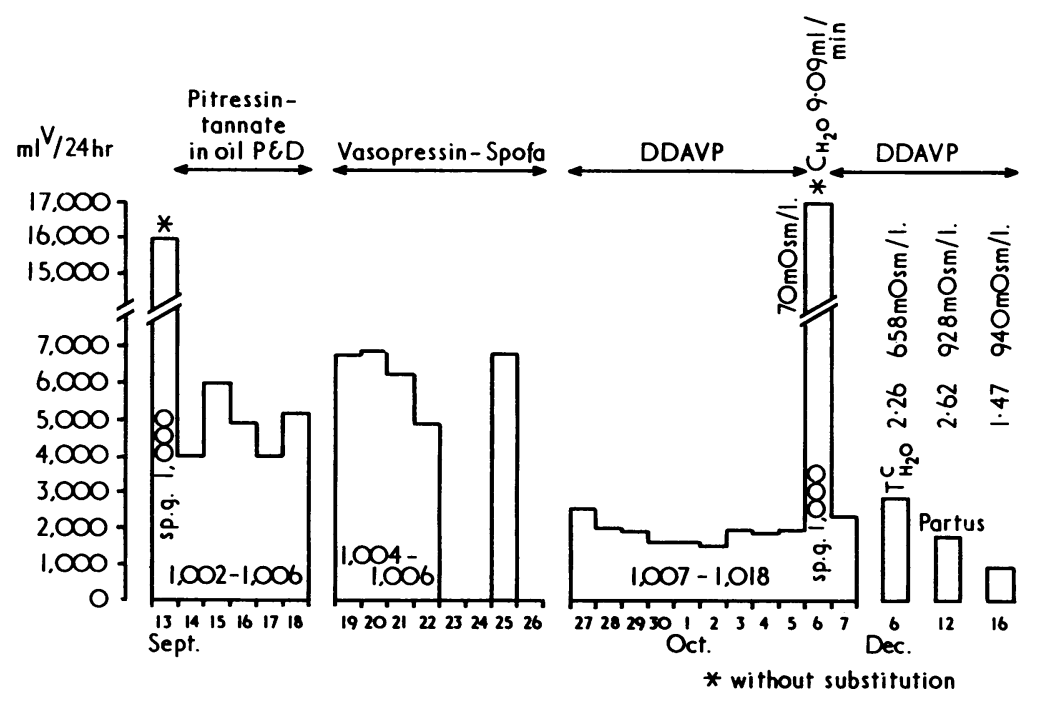

maximum level of $17 \mathrm{l}$. of urine daily, 70 mOsm/1., with a free water clearance of 9.09 $\mathrm{ml} / \mathrm{min}$. The maximum therapeutic effect of Pitressin-tannate in oil twice daily and, subsequently, intranasal vasopressin (up to 70 drops daily; $1 \mathrm{ml}=50 \mathrm{IU}$ ) reduced urine output to only 5-6 $1 . /$ day. The specific gravity of the urine never rose above 1006 and the patient was not relieved of symptoms of thirst and depression. Shortly after each administration there were strong, painful, and very prolonged uterine contractions. $\mathrm{B}$ cause of the contraction she was switched over to intranasal drops of aqueous DDAVP. A dose of $15 \mu \mathrm{g}$ DDAVP (three drops) was given eight hours into the nose. Her daily urine output immediately came down to 21 . a day and urine specific gravity increased to 1010-1027, maximum $900 \mathrm{mOsm} / \mathrm{l}$. There was no uterotonic or other reaction to this dosage, and thirst and depression disappeared. When antithyroid drugs were omitted the daily urine output on the same DDAVP dosage increased to 31 . a day.

A fortnight before her calculated term, the patient gave spontaneous birth to a fullydeveloped baby. The patient continues to be maintained on DDAVP at her own insistence, and shows no signs even of local mucosal irritations in the nose. The results are summarized in the Figure.-I am, etc.

IIIrd Clinic of Internal Medicine,

D. Oravec

The Commenius University,

Bratislava, Czechoslovakia

B. Lichardus

Institute of Experimental Endocrinology,

Slovak Academy of Sciences,

1 Zaoral, M., Kolc, J., and Sorm, F., Collection of Czechoslovak Chemical Communications, 1967, 32, 1250.

2 Andersson, K. -E., and Arner, B., British Medical fournal, 1971, 3, 111.

3 Vávra, I., et al., Lancet, 1968, 1, 948.

\section{Pyrexia with Cytosine Arabinoside}

SIR,-Fever is stated to be an unusual side effect of cytosine arabinoside. ${ }^{1}$ We have recently treated a 67-year-old man with acute myelomonocytic leukaemia in whom a remarkable febrile reaction occurred. We were initially unaware that this could be attributed to cytosine and contemplated a variety of explanations which we were unable to substantiate. Blood and urine cultures, viral studies, serological tests for brucellosis, and chest radiographs were all normal. The following report is submitted to draw attention to this complication.

The patient's first symptom was severe pain in the abdomen over a grossly enlarged spleen. Acute myelomonoblastic leukaemia was diagnosed from blood and bone marrow features. The blood film and haemoglobin electrophoresis were also characteristic for $\beta$-thalassaemia trait. Though the blood contained 30,000 blast cells per $\mu l$ the patient was neither neutropenic nor thrombocytopenic. In view of his curious mode of presentation we considered that the acute leukaemia may have supervened on an undiagnosed pre-existing chronic myeloproliferative disorder, but we have no objective evidence to support this.

Treatment was started with intravenous daunorubicin (110 $\mathrm{mg}$ on the first day only) and cytosine arabinoside $\mathbf{( 7 2 . 5} \mathrm{mg} 12$ hourly for five days). The temperature is shown in the Chart. From the start of the treatment the patient had periodic severe rigors. It can be seen that the fever subsided after the completion of the course of treatment. The next schedule of treatment 12 days later employed half as much daunorubicin and cytosine as the previous course. The patient developed an erythematous itching skin rash over his trunk which subsided after 10 days.

When the third therapeutic course was begun one week later at full dosage the patient had been afebrile for a fortnight. Within a few minutes of administration of the first dose of both drugs he developed a rigor and the temperature rose to $39^{\circ} \mathrm{C}$. Subsequent doses of cytosine were given with $100 \mathrm{mg}$ hydrocortisone and no further reactions have taken place. It is intriguing that after it had been that of Dr. M. Kremer and others (22 July, concluded that cytosine arabinoside was p. 216).

responsible for the hectic exacerbation of pyrexia the result of a toxoplasma dye test was received which was strongly positive. The initial titre was $1: 2,000$, rising to 1:4,000 after three weeks. Perhaps a previously quiescent toxoplasma infection became active with the development of the acute leukaemia and may have been responsible for the less striking pyrexia which flanked the cytosine therapy.

We are grateful to Professor M. H. Lessof for permission to publish this report of a patient under his care.-We are, etc.,

M. S. Ros:

Guy's Hospital,

D. N. Bateman

London S.E

1 Upjohn Ltd., Literature on Cytosan.

\section{Potentiation of Barbiturate by Ouabain}

SIR,-In view of the current concern over the unexpected marked increase in bioavailability of digoxin present in Lanoxin tablets I should like to draw attention to the possible clinical significance of some experiments I have been conducting concerning a barbiturate-cardiac glycoside interaction.

These experiments, performed in mice, have shown that a pronounced increase in barbiturate potency can be brought about by ouabain through a direct interaction at the level of the central nervous system. Since the ratio of therapeutic dose to toxic dose is small for the cardiac glycosides, and since their toxicity is made manifest by central nervous symptoms, the possibility of unexpected increases in barbiturate potency in patients receiving combined cardiac glycoside and barbiturate therapy should be borne in mind, particularly when a change of dosage form results in increased bioavailability of the cardiac glycoside.

These findings have been submitted in extenso for publication in Archives Internationales de Pharmacodynamie et de Thérapie.-I am, etc.,

\section{N. S. DOGGETT}

Department of Pharmacology

Un versity of Wales Institute of Science and Technology,

\section{Neurological Deficits in Primary Polycythaemia}

In 1969 a man aged 58 with chronic schizo-

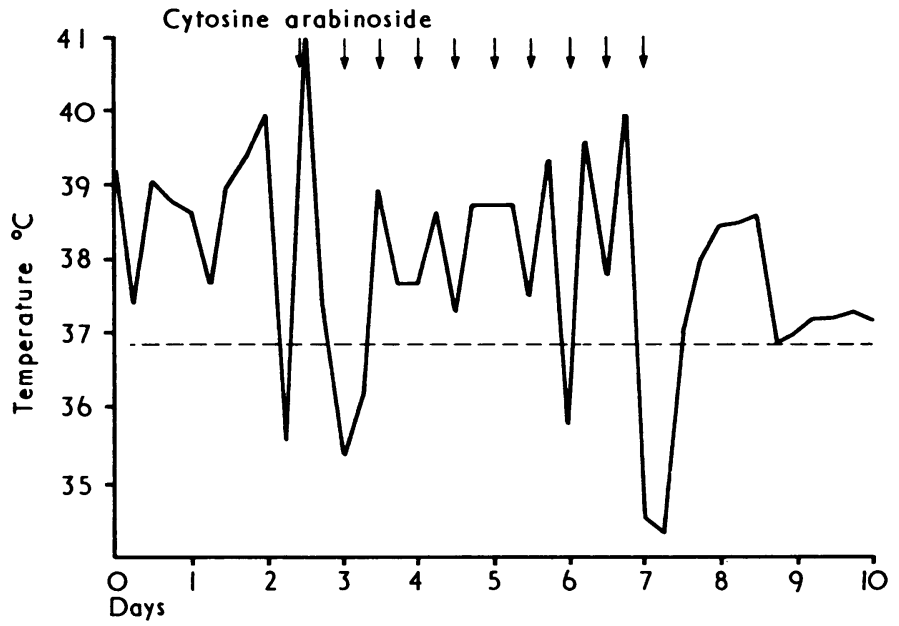

